\title{
YORUM COMMENTARY
}

\section{Psikiyatrik Açıdan Akıl ve Aklın Terbiyesi Psychiatric Aspects of Reason and Morality of Reason}

\author{
Osman Özdemir
}

\begin{abstract}
$\ddot{0 z z}$
Akıl bizi neyin iyi ve doğru, neyin yanlış ve kötü olduğu bilgisine ulaştııır. Akıl yürütme, bir konuda yeterli düzeyde kanıt ve bilgi sahibi olduktan sonra bütün etmenleri dikkate alarak düşünüp bir sonuca ulaşma sürecidir. Akıl sahibi insan yeni karşılaştığı durumu tüm boyutlarılla inceler, mantıklı tahminlerde, varsayımlarda bulunur, bazı sonuçlara ulaşır, düşüncelerini açıklayabilir ve ulaştığı sonucu savunabilir. Bazı düşünürlere göre doğru ve yanlış bir hareket tarzını seçmeye sevk eden sebepler olarak tanımlanabilecek ahlakın temel prensiplerinin kaynağı akıldır. Bu açıdan akıl ve irade sahibi her insan yaptığı davranışlardan ahlaki olarak sorumludur. Genetik ve çevresel faktörler direkt ya da dolaylı olarak ahlaki gelişimi etkileyebilir. Bu yazıda alınan eğitim ve alt kültürün terbiye üzerindeki etkisinin vurgulanması amaçlanmıştır.

Anahtar sözcükler: Akıl, eğitim, terbiye.

Abstract

Reason allows us to arrive at knowledge of what is good and true and what is wrong and evil. Reasoning is a process to reach a conclusion by taking all related factors into account if there are enough evidence and information. Humans who have reasoning skills must analyze new situation which are faced in all aspects, explore, make logical inferences, explain his thoughts, reach conclusions and protect his conclusions. Some thinkers argue that reason is the source of morality that makes the distinction between right and wrong behaviour. In this respect, everyone who has mind and will has morality responsibility for their actions. This paper aims to emphasize the importance of received education and subculture on the moral development that can be directly or indirectly influenced by genetic and environmental factors.
\end{abstract}

Key words: Reason, education, morality.

AKIL kelimesi etimolojik (köken) olarak, bağlamak, engelleme, yasaklama, tutmak, korumak gibi anlamlara gelmektedir (Emiroğlu 1998, Esen 2011, Köle 2013). Zıdd1 ahmaklık ve aptallık olup, fikirleri birbirine bağlayarak akıl yürütme rolünü oynadığ1 (bağlamak), yeni bilgiler elde edebildiği (tutmak), insanı tehlikelere karşı koruyabildiği (engelleme) için bu ad verilmiştir. Burada bağlamaktan maksat birbirine uygun iki nesne veya iki kavram arasında bağlantı kurmaktır. Mesela kalem ve yazmak kelimeleri arasında uygun bir bağıntı (ilişki) vardır: bu suretle kalem yazıyor önermesi akla uygundur. Terim olarak duyu organları aracilı̆̆ı ile kendisine ulaşan bilgileri değerlendirebilme, bilinenlerden yola çıarak bilinmeyenlerin anlama, kavramlar arasında ilişki kurarak sonuçlar ortaya koyabilme, kıyas yapabilme, doğru ve yanlışı, iyiyi ve kötüyü ayırt ede- 
bilme yeteneğidir (Esen 2011). Aklın en önemli görevlerinden biri dış dünyadan malzeme alarak bilgi üretmesi, gerçekle gerçek olmayanı birbirinden ayırmasıdır. İnsanın her türlü eylemine anlam kazandıran ve onun sorumlu tutulmasını gerektiren yine akıldır (Emiroğlu 1998, Köle 2013).

Akıl sağlığı ve hastalıklarıyla ilgilenen psikiyatride akıl ile ilgili teorik tartışma ve tanımlamaların yer aldığı yazılı metinlerin olmadığı söylenebilir. Bu alandaki yazılar daha çok din ve felsefe literatürlerinde yer almaktadır. Bu yazıda ilgili literatürler ışığında psikiyatride akıl ve psikoterapi ile ilgili olduğu düşünülen aklın terbiyesi konusu ele alınmaya çalışılacaktır.

\section{Din Literatüründe Akıl}

Din literatüründe akıl insanın hakla bâtılı birbirinden ayırma özelliği, onu fenalıklardan alıkoyup iyiliklere yönlendiren güç anlamlarında kullanılabilmektedir. Yine dini düşünceye göre akıl bilginin kaynaklarından biridir ve sorumlulukların kaynağıdır. Aklı olmayan, ne yaptığını bilmeyen, olayların önünü arkasını tefrik ve temyiz edemeyen (farik ve mümeyyiz olmayan) kişi dini sorumluluklarda yükümlü tutulmamıştır. Din düşünürlerine göre akıl insanın kâinatta olup biten hadiseleri değerlendirerek Yaratıcıya ulaşmasını sağlayan anlayışın aracıdır (Esen 2011). Bu araç onu aynı zamanda Yaratıcıya muhatap haline getirir. Semavi (yaratıcıdan gelen) mesajları referans alarak insanı fenalık ve çirkinliklere karşı koruyan, iyilik ve güzelliklere ulaştıran yine akıldır. Bazı dini kaynaklara göre akli olan konular "makul" ve akli olmayanlar "muhal (imkansız)" olarak kabul edilmektedir. Bu açıdan ilahi icraata bağlanmayan, tesadüf ve neden sonuç ilişkisi ile açıklanmaya çalış1lan tabiat ve varlığın kendi kendine oldu düşüncesi muhal anlayışı temsil etmektedir.

\section{Felsefede Akıl}

Akıl terimi Yunancada varlığın özü olan logos anlamında kullanılır (Öner 2009, Saldıray 2011). Herakleitos (MÖ. 540-479) tarafindan logos, sürekli hareket ve değişim halinde olan evrende tüm olaylara etki eden, mevcut düzeni devam ettiren bir ölçü, mantıksal temel ve doğanın yasası biçiminde tanımlanmıştır (Öner 2009). Buna göre rastlantı ve gelişigüzel karşıtı olan logos oluşumların altında yatan ve onları biçimlendiren evrensel akıl demektir. Bu aklın bir parçası da insandaki akıldır (Öner 2009, Sald1ray 2011). İlk çağ filozoflarından Platon (MÖ. 429-348) ve hocası Sokrates (MÖ. 469399) aklın doğuştan bilgilerle donatılarak geldiğini, dünya da sadece bunların hatırladığını kabul ederler. Dogmatizm olarak adlandırılan bu anlayışa göre doğuştan (a priori) gelen ve asla değişmeyeceği kabul edilen mutlak değerler (dogma) dışında bir gerçek bulunmamaktadır ve bu gerçekler tartışmaya veya incelemeye ihtiyaç duymamaktadır (Öner 2009). İnsan bilgisi kesin ve mutlak olduğunu, duyularımızın, aklımızın bildiklerinin dışında bir gerçek olmadığını savunan dogmatiklere karşın şüpheciler (septikler) insanın mutlak olarak hiçbir şeyi bilemeyeceğini, aklın kesin bir bilgiyi elde edemeyeceğini, en kesin bilgilerimizde bile şüphe edilecek bir yön olduğunu öne sürerek her türlü bilgiyi kuşkuyla karşılamışlardır (Öner 2009). On yedinci yüzyılda felsefenin önde gelen isimlerinden Descartes'e göre (1599-1650) kesin bilgi mevcuttur, şüphecilik ise kesin bilgiyi bulana kadar tüm bilgileri gözden geçirme yöntemidir. Ona göre akıl, iyi hüküm verme ve doğruyu yanlıştan ayırma gücüdür ve bütün insanlarda eşit olarak bulunmak- 
tadır (Öner 2009). Benzer şekilde bilgiyi duyumlar ya da izlenimlere dayandıran David Hume (1711-1776) zihin yetilerinin ve akla uygun kararların alınması esnasında yapılan değerlendirme sürecinin her insanda aynı olduğunu savunur. Hume’a göre akıl duyuların verdiği malzemeyle sınırlı bir yeti olarak doğruluğun ve yanlışlığın ortaya çıkarılması görevini yerine getirebilir, geçmiş gözlem ve deneylere dayanarak bilinen durumlar ve bağlantılardan yeni ve bilinmeyen bir durum hakkında sonuçlar çıkarır (Ketenci 2016).

Batı toplumunda aydınlanma çağ hareketlerinin de etkisi ile akılcılık (rasyonalizm) felsefesi ağırlık kazanmıştır. Aristo ile başlayarak gelişen akılcılık, bilginin kaynağının akıl olduğunu; doğru bilginin deneyim ve alg1 olmaksızın mantık ve akıl yürütme ile elde edilebileceğini savunmuştur. Buna göre, doğa ile akıl, madde ile zihin arasında tam bir (epistemiyolojik) uygunluk olduğu için insan matematiksel kavramlarla evrendeki her şeyi kavrayabilecektir (Öner 2009). Akılcılık düşüncesine göre bilgilerin kaynağı apriori ya da deney öncesi akılcı sezgilerdir. Bilgi bu sezgilerin akıl yoluyla kavranması ile elde edilebilmektedir. Zamanla sadece akıl yürütme ve mantık yoluyla doğrulara ulaşmanın mümkün olmadığı, deney ve gözlem yapmanın önemli olduğu vurgulanmaya başlandı. Boş bir levha gibi insan zihninde doğuştan bir bilgi olmadığını savunan deneyci görüşe göre bilgiler sonradan deney ve gözlemlerle (a posteriori), duyular aracılı̆gı ile kazanabilmektedir. A priori ve a posteriori bilginin varlığını kabul eden aydınlanma çağının en önemli düşünürlerinden Immanuel Kant (1724-1804) teorik akıl ile değil ancak düşünce üreten ve anlamaya çalışan pratik akıl aracılığı ile doğru bilgilere ulaşılabileceğini savunur (Köle 2013, Zamanlou 2015).

\section{Akıl ve Zekâ Ayrımı}

Zeki kelimesi köken olarak parlak ateş, parlaklık ve keskinlik anlamlarına gelmektedir. Kavram olarak zekâ zihnin öğrenme, öğrenilenlerden yararlanabilme, yeni durumlara uyabilme ve yeni çözüm yolları bulabilme yeteneğidir. Psikiyatride problem çözme, planlama, soyut düşünme, yargılama, öğrenme yetileri anlamında kullanılmaktadır. Zekâ yetersizliğinde eğitim, iletişim, toplumsal paylaşım, bağımsız hareket edebilme, günlük yaşam ve mesleki işlevsellik, alanlarında bozulmalar görülebilir (Amerikan Psikiyatri Birliği 2013). Zekânın duyular ve sezgiler aracılığı ile çevreden veri topladığı, öğrenme ve ezber yaptığ1, ancak bu verileri değerlendiren, onaylayan, karar veren ve son seçimi yapanın akıl olduğu belirtilmektedir. Bir otomobil örneğinde zekânın motor, aklın direksiyon görevi gördüğü benzetmesi yapılarak aklın zekâyı kullandığı ve yönlendirdiği vurgulanmaktadır. Ayrıca, aklın bilinen konularda, zekânın ise daha çok bilinmeyen konularda görev aldığı düşünülmektedir (Demir 2009). Bir diğer farklilık olarak aklın doğuştan her insanda var olduğu, zekânın ise sonradan geliştirilebildiği söylenebilir.

\section{Aklın Fonksiyonu}

Aklın eldeki verileri değerlendirerek sebep sonuç ilişkisine göre bir karara ulaşması ve sonucundan sorumlu olduğu bir davranı̧̧ sergilemesi beklenir (Yetiş 2004, Çelik 2008). Akıl bu değerlendirme sürecinde ortaya çıkacak fiilin uygun olması halinde övülebileceğinin, aksi takdirde ise kınama ve ceza görebileceğinin farkındadır. Bu nedenle akıl belli metodlara bağlı kalarak araştırmaya, delillere ve daha kesin bilgiye dayanan objektif bir 
bilgi sonucuna göre hareket etmelidir (Çelik 2008, Esen 2011). Delil, herhangi bir konu hakkında karar verme sürecinde yol gösteren ve sonuca götüren ölçüt olarak kabul edilebilir (Şahin 2015). Delil, iddialardan doğru çıkarımlar yaparak mevcut kanaatin akla ve gerçeğe uygun olup olmadığının açıklığa kavuşturulmasını sağlayan araçtır (Gündem 2011, Yayla 2013 ). Anglo-sakson hukukunda uygulandığ1 üzere iddia sahibinin ithamını ispat etme zorunluğu bulunmaktadır (Yayla 2013). Delile dayanmayan, sadece bir şüpheden ibaret bulunan basit iddialara dayanarak derhal bir kanaate varmak akla uygun değildir.25 Burada aklın fonksiyonu iddiayı destekleyen ve desteklemeyen mevcut tüm verilerin değerlendirilmesi ile neticeye varmaktır (Gündem 2011).

\section{Aklın Terbiyesi}

Gereken zekâya, ayırt etme gücüne sahip olduğu halde kendinden beklenen kararları veremeyen ve davranışları sergileyemeyen aklın görevini yerine getiremediği açıktır. Bu açıdan sadece iyiliği ve kötülüğü tanıyan değil; iyiliği tanıyıp ve aynı zamanda gereğince hareket eden, kötülüğü tanıyıp ondan sakınan kimsenin akıllı olduğu ifade edilmiştir (Köle 2013). Aklın uygun referanslar ışığında ve doğru bilgiler eşliğinde eğitim ile kazanılan terbiye yoluyla makul kararları verebilecek potansiyele ulaşabileceği düşünülmektedir. Onun ilk oluşan şüpheye göre değil; bütünü yeterli bilgi düzeyi ile birlikte farklı boyutlarıyla dikkate alarak muhakeme ettikten sonra bazı sonuçlara ulaşması ve ulaştığı bu sonucu savunabilmesi beklenir (Umay 2003). Aktif olan bu akıl kanıtı bulunan düşünceler arasında ilişkiler kurarak sahibinin işlerini kolaylaştıracak yeni hükümlere ulaşabilir (Hasırcı 2005). Aksi takdirde güvenilir öncüller üzerine temellendirilmeyen, gerekçelendirilemeyen, mantıklı yaklaşımlar içermeyen, sadece kendi kendine yapılan ve görünüşte geçerli kabul edilen kişisel çıkarımlar vasıtasıyla herhangi bir çözüme ulaşılamaz (Umay 2003, Hasırcı 2005). Doğru kararlar verebilen aklıselim sahibi bireylerin yetişmesi ancak terbiye kavramını esas alarak benimseyen ve olumlu davranışlar kazandırmayı hedefleyen bir eğitim ve kültür anlayışından geçebilir (Umay 2003).

Bireyler kendi temel inançları ve kuralları çerçevesinde olayları değerlendirir ve buna göre davranırlar. Eğer kişi diğer insanların kötü oldukları için kuşkuyla yaklaşılması gerektiğine dair baştan katı ve olumsuz önyargılara sahip bulunuyorsa o zaman sorun yaşamaya ve yaşatmaya başlayabilir (Türkçapar 2009). Bu tür insanların düşünce sisteminde yeterli bir temele dayanmayan başkalarının hareketlerini kötü niyetli olarak yorumlama, başkalarının kendisini aldattığından şüphelenme, çalışma arkadaşlarıyla ilgili yersiz kuşkularla uğraşıp durma, sıradan sözlerden ya da olaylardan aşağılama ya da göz korkutma anlamı çıkarma eğilimi olabilir. Ayrıca ortada bir neden yokken başkalarının kimi davranışlarını kişiliğine ya da saygınlığına bir saldırı olarak algılama ve olduğunu kabul ettikleri aşağılamaları ya da saygısızlıkları bağışlayıcı olmadıkları için öfkeyle karşılık verme, karşı saldırıya geçme ve sürekli kin besleme durumları görülebilir (Amerikan Psikiyatri Birliği 2013).

Oysa dış gözle daha objektif baktığımızda aslında yaşanan olayların herkesin başına gelebilen, sadece bir kişiyle ilişkili olmayan, kendinden önce ve sonra gerçekleşen diğer olaylar üzerinde etki gücü bulunmayan geçici bir durum olduğu anlaşılabilir. Burada insanların değerlendirme biçimlerini olumsuz etkileyebilen duygular sağlıklı muhakeme yapmayı engelleyebilir (Türkçapar 2009). Kendisi, diğer insanlar ve dünyanın işleyişi ile ilgili nesnel bir değerlendirme yap(a)mayan ve gerçekliğe uymayan düşüncelerin etkisinde kalan insanlar yaşadığı durumun gerektirdiğinden daha olumsuz duygular yaşaya- 
bilir (Türkçapar 2009). Yaşam olayları ve çevre arasındaki dinamik etkileşim sonucu aktive olduklarında kişi açısından çok sıkıntı verici olan mutlak inançlarla ilgili farkındalık gelişmedikçe ve bunları değiştirmedikçe küçük bir olaydan etkilenme sonucu sorun yaşama ihtimali yüksektir (Türkçapar 2009). Hafif durumlarda kişi genellikle olumsuz düşüncelerini daha nesnel görebilse de durum ilerledikçe olay ve kişinin olumsuz yorumlamaları arasında mantıksal bir bağlantı olmamasına karşın düşünme giderek disfonksiyonel otomatik mutlak inanı̧̧ların egemenliğine girebilir. Bu inanı̧̧lar gerçeklikte bozukluklara yol açtığ1 ve bunun sonucu olarak kişinin düşünmesinde sistematik hatalar olduğu için kişi olumsuz yorumlamalarının hatalı olabileceği fikrini pek kabul edemeyebilir. Bu gibi durumlarda dış gerçeklerden bağımsız kişinin zihni ısrarlı ve tekrarlı olumsuz düşüncelerle uğraşır ve istemli zihinsel etkinliklerde bulunmada, uyaranları doğru algılamakta, çevresindeki değişikliklere uygun yanıt vermekte zorlanabilir (Arkar 1992).

Hem olumlu hem de olumsuz inançları bulunan sağlıklı insanların sorunları nedeniyle geçici olarak geri plana itilen olumlu inançları olağan koşullarda yeniden baskın hale gelir, olumsuz olanlar pasif duruma geçer, kişi tekrar uyumlu bir yaşam sürmeye devam eder (Türkçapar 2009). Fırsat sunulması halinde yapılan görüşmede önyargılarına uyan verilere önem verdiği ve böylece onları sürdürdüğü, önyargılarına uymayan noktaları ya görmezlikten geldiği veya olanları kendisine uygun açılardan ele alarak olumsuz yorum yaptığı kişiye açıklanabilir. Alternatif bakış açıları sayesinde daha önce yapmış olduğu olumsuz yorumlamaların yanlış olduğu konusunda ikna edilebilir, bu yolla olumsuz sonuçlara ulaşmak için gerçekleri nasıl değiştirdiğinin farkına varabilir (Arkar 1992). Bireyin yaşam olaylarında etkinliğini arttırmak ve bilişsel değişikliği kolaylaştırmak amacıyla ilk müdahale alanı değiştirebileceği davranışlar olabilir (Türkçapar 2009).

Disfonksiyonel inançları belirlemek, gerçeklik açısından test etmek ve düzeltmek için zamanın akışı içinde daha önceki deneyimlerle gelişen tutumlara ve kabullere dayanarak kişinin dünyayı nasıl ve yollarla tasarladığı bulunabilir (Arkar 1992). Sorunları ile ilgili gerçekçi ve daha uyum sağlayıcı düşünme ve hareket etmesine yardımcı olabilmek amacıyla donanımlı ve deneyimli rehberler eşliğinde kişinin özgül hatalı kavramlaştırmaları ve uyuma yönelik olmayan varsayımları test edilerek tanımlanabilir. Sağlam bir bilgi zemini üzerine inşa edilen bu yaklaşımın gözlenen en güçlü yanlarından bir diğeri açılanamayan kalıplaşmı̧ otomatik örüntüleri sınırlandırarak temelleri keşfedilen sonuçlarda kişilerin kendilerini sorgulamayı öğrenmeleridir. Yine bu yaklaşımın genel stratejisi kişinin kendi deneyimlediği çıkarsamalardan vardığı sonuçların varsayımlar şeklinde formüle edilerek neden-sonuç ilişkisi açısından geçerliliğinin sistematik olarak araştırılmasına yönlendirilmesidir (Arkar 1992).

\section{Akıl ve Ahlak}

"Yapılması ve yapılmaması gereken davranışlara ilişkin kurallar", "doğru ve yanlış bir hareket tarzını seçmeye sevk eden sebepler" olarak tanımlanabilecek ahlakın temel prensiplerinin kaynağı Kant’a göre akıldır (Kılıç 1993). Aslında akıl ve ahlak ilişkisinin kökleri insanın kendisi ve evrenin varlığının anlamını zihinsel bir çaba ile kavrayabileceğine inanan Sokrates ve en yüce hakikatın ancak müzakere ile ortaya çıkabileceğini savunan Platona kadar uzanır (Gündüz 2010). Kant'ı takiben bilişsel gelişimsel paradigmayı oluşturan Jean Piaget (1896-1980) ve Lawrence Kohlberg (1927-1987) ahlaki- 
likle ilgili en ayırt edici özelliğin akıl yürütme kapasitesi olduğunu vurgulamışlardır (Ekşi 2006).

Ahlak gelişimi üzerine ilk çalışmaları yapan araştırmacı olan Piaget ahlak gelişiminin zihinsel gelişim ile oluştuğunu, bilişsel gelişim için geçerli olan ilkelerin ahlaki gelişim için de geçerli olduğunu, yaşı ne olursa olsun her bireyin bilişsel gelişimin son basamaklarına kadar ulaşabilmesinin mümkün olmadığını ifade etmiştir. Yine bu alanda incelemeler yapan Kohlberg ahlakı iyi-kötü konularında bilinçli yargılama, karar verme ve bu karar doğrultuda davranışta bulunmayı içeren bilişsel bir yapı olarak tanımlar (Ekşi 2006). Bilişsel ahlak gelişim kuramı bireyin sosyal ve kültürel çevresine bağımlı olarak kendi koşulları içerisinde ahlak gelişimini sürdürdüğünü, ahlak yargılarındaki tutarlılığın ancak ahlaksal düşüncenin davranışa yansıması halinde mümkün olabileceğini vurgular. Gelişim psikoloji açısından akıl yürütme kapasitesi bireylerin duygu, düşünce, yarg1, tutum ve davranışlar gibi tüm etkinliklerini yönlendiren ölçüt olarak kabul edilmesine karşın günümüzde genel olarak davranışa yön veren faktörler arasında ahlaki akıl yürütme yerine duygu temelli yaklaşımların önemli payı olduğu görülmektedir (Gündüz 2010). Halbuki sorumluluk bilinci olan terbiyeli bir kimseden yaptığ maksatlı davranışı dikkatli incelemeden geçirmesi, öncesi ve sonrasını derinliğine düşünmesi beklenir (Yalın 2015). Bu açıdan akıl ve irade sahibi her insan kasıtlı yaptığı eylemlerden ve taşımış olduğu niyetlerden ahlaki olarak sorumludur. İnsanların günlük yaşamlarında yapageldikleri davranışlara yön veren ahlaki ilkeler doğuştan gelen özellikler dahil olmak üzere çevre, toplum, zaman, mekân ve tecrübe gibi değişkenlerin etkisinde kalabilir. Burada iyiyi ve kötüyü birbirinden ayıran akıl sahipleri hür iradeleriyle karar verip yaptıkları her türlü eylemden sorumludur (Güneş 2011).

\section{Sonuç}

İnsan sadece etrafında olup bitenler hakkında teoriler kuran zekâya değil bunun yanında doğru bilgilere dayanarak nasıl davranması gerektiği konusunda kendisine yol gösteren işlevsel bir akla sahip olduğunda gerçeğe ulaşabilir. Sağlıklı zihnin en önemli özelliği ötekinden şüphe ettiğinde bu doğrultuda hemen hareket etmeden önce emin olmak için değerlendirme yapabilmesi, yanılma ihtimaline karşı geri adım atma olasılı̆̆ına da tahammül edebilmesidir. Akıl bu süreçte elindeki verilerin doğru işlenmesi ve değerlendirilmesi için bilgi birikimine, tecrübeye ve sağlam temeli olan değer yargılarına gereksinim duyar. Aklı işlev göremez duruma sokmamak, önyargılardan ve şartlanmışlıklardan arındırmak, aşırılıklardan kurtarmak ve onu gerçek amacına uygun kullanabilmek için yaşantıya dayalı bir terbiye sistemine ihtiyaç vardır.

\section{Kaynaklar}

Amerikan Psikiyatri Birliği (2013) Ruhsal Bozuklukların Tanısal ve Sayımsal Elkitabı, Beşinci Baskı (DSM-5), Tanı Ölçütleri Başvuru Elkitabı (Çev. Ed.: E Köroğlu). Ankara, Hekimler Yayın Birliği.

Arkar H. (1992). Beck'in depresyon modeli ve bilişsel terapisi Düşünen Adam: Psikiyatri ve Nörolojik Bilimler Dergisi, 5:37-40. Çelik I (2008) Muhammed İkbal'de akıl ve aşk. Tasavvuf IIImî ve Akademik Araştırma Dergisi, 22:23-57.

Demir H (2009) Aklı geliştirmenin yolları. http://elibrary.bsu.az/books_aysel\%5CN_402.pdf (19 temmuz 2016 da ulaşıldı) Ekşi H. (2006). Bilişsel ahlak gelişimi kuramı: Kohlberg ve sonrası. Abant İzzet Baysal Üniversitesi Eğitim Fakültesi Dergisi, 6: 2938.

Emiroğlu I (1998) Kuranda akıl ve insan. Dokuz Eylül Üniversitesi Illahiyat Fakültesi Dergisi,9: 69-99.

Esen M (2011) Kuranda iman akıl ilişkisi. Ankara Üniversitesi İlahiyat Fakültesi Dergisi,52: 85-96.

Gündem K (2011) CMK m.138 çerçevesinde tesadüfen elde edilen deliller (Yüksek lisans tezi). Konya, Selçuk Üniversitesi. 
Gündüz T (2010). Üstün Zekâlı Çocuklarda Ahlâk Gelişimi ve Eğitimi. I.ü. Ilahiyat Fakültesi Dergisi, 1:157-177.

Güneş Y (2011). İslam ahlakının temel özellikleri. Ekev Akademi Dergisi, 49:93-104.

Hasırcı N (2005) John Stuart Mill'in tümevarım anlayışı (Doktora tezi). Ankara, Ankara Üniversitesi.

Ketenci T (2016) Descartes ve Hume'un akıl anlayışlarının karşılaştırılması. http://www.temasa.org/wp-content/uploads/ 2016/sayi1/61-77.pdf (19 temmuz 2016 da ulaşıldı).

Kılıç R (1993) Ahlakın temellendirme problemi. Felsefe Dünyası, 8:67-78.

Köle B (2013) Tasavvufa göre ilâhî hakikatlerin idrâkinde aklın konumu. Iğdır Üniversitesi Sosyal Bilimler Dergisi,3: 81-96.

Öner E (2009) Kant'ta aklın eleştirisi (Yüksek lisans tezi). Rize, Rize Üniversitesi.

Saldıray A (2011) Aristoles felsefesinde "öz" ve "biçim" kavramları (Yüksek lisans tezi). Diyarbakıı, Dicle Üniversitesi.

Şahin H (2015) Kelamcılara göre delil ve delil türleri. Kelam araştırmaları, 13:453-472.

Türkçapar H (2009) Klinik uygulamada bilişsel davranış̧ı terapi: Depresyon. Ankara,Hekimler Yayın Birliği.

Umay A (2003) Matematiksel muhakeme yeteneği. Hacettepe Üniversitesi Eğitim Fakültesi Dergisi, 24 : 234-243.

Yalın S (2015) Ahmet Hamdi Akseki'de ahlaki sorumluluk. Sosyal Bilimler Enstitüsü Dergisi Sayı, 38:209-225.

Yayla M (2013) Ceza yargllanmasında ispat için yenilmesi gereken şüphe; Türkiye ve Amerika Birleşik Devletleri sistemlerinin incelenmesi, Ankara Barosu Dergisi, 3:289-314.

Yetiş K (2004) Garipname'de akıl. İstanbul Üniversitesi Türk Dili ve Edebiyatı Dergisi, 31:357-380.

Zamanlou H (2015) Martin Heidegger ve teknolojinin hermeneutik ontolojisi (Yüksek lisans tezi). Ankara, Hacattepe Üniversitesi.

Osman Özdemir, Yüzüncü Yıl Üniversitesi, Van.

Yazışma Adresi/Correspondence: Osman Özdemir, Yüzüncü Yıl Üniversitesi Tıp Fakültesi Psikiyatri AD, Van, Turkey.

E-mail: drosmanozdemir@yahoo.com

Bu makale ile ilgili herhangi bir çıar çaıı̧̧ası bildirilmemiştir · No conflict of interest is declared related to this article

Çevrimiçi adresi / Available online: www.cappsy.org/archives/vol9/no1/

Geliş tarihi/Submission date: 1 Haziran/June 1, 2016 · Kabul Tarihi/Accepted 24 Haziran/June 24, 2016 